\title{
WORLD DIGEST OF METEOROLOGICAL DATA
}

\author{
By W. J. HuMphreys
}

Meteorological data are gathered for, and serve, many purposes:

They are abundantly used in forecasting the weather of the morrow, but obviously used only once, and hence for this purpose need not be recorded.

They also are collected in the course of special studies, but the completion of each investigation renders useless the preservation of the particular material treated. It is the generalization - the law-that counts, and not the isolated values from which it happened to be deduced.

Finally, they are essential to many studies of interrelations between meteorological elements; to a knowledge of the relation of the weather in one part of the world to that occurring either previously, simultaneously, or subsequently, in others; and to all accurate knowledge of climates and their changes. For each of these purposes it is necessary that meteorological data be indefinitely accumulated, and equally necessary that they be put in manageable form and made widely available.

Now, although fully three-fourths of the surface of the earth is a meteorological blank, the mass of data already accumulated from the remaining one-fourth is so vast and heterogeneous as to be beyond the power of any individual to analyze and study in detail. Furthermore, even approximately complete sets of these data have been assembled in very few places. Hence much of the information contained in this meteorological material certainly is not only unknown, but even beyond the power of individual effort to know.

Therefore it is suggested that a comprehensive digest of all existing meteorological data be made and published. A possible way of accomplishing this great labor is as follows :

1. Let the data to be published (monthly and annual normals and departures therefrom, special phenomena, and what not), the units to be used, the form of publication, and all other details of this kind, be agreed to internationally.

2. Let each country furnish the digest of its own data.

3. Let the digest for each country consist of the individual digests for, and made at, its several meteorological stations.

4. Let some one agency, supplied with adequate funds and personnel, be charged with the duty of assembling sporadic data from countries that have no official meteorological organization; and with the further important duty of editing the entire work.

In this way the proposed vast labor would be divided up between several countries, and further subdivided among many individuals in each country, and the product of the combined effort of the many workersthe digest of all the world's meteorological data-soon made available to every institution that needs it and to every individual who wishes to study it. 
There then could be students of world meteorological data, and would be; now there is none-and can not be.

It will be recognized of course that the plea here is for a greater "Réseau Mondial," one covering a larger number of meteorological elements than does that splendid publication, and also extending back to the beginning of meteorological observations. It would both include and supplement the data contained in the present Réseau Mondial, but would not take the latter's place as a convenient annual summary of the more important elements of the world's weather at selected places.

\section{GENERAL ADOPTION OF THE CENTESIMAL SYSTEM OF ANGULAR MEASUREMENT-WITH APPLICATION TO ANEMOMETERS AND NEPHOSCOPES}

\section{By Alexander McAdie}

Reviewing an article on "Uniformity in Aerographic Notation," 1 Sir Napier Shaw ${ }^{2}$ calls attention to the common usage of the capital letters N.E.S.W. for wind directions, and the established usage in Physics of $\mathrm{N}$ for Avogadro's constant, $\mathrm{E}$ for Energy, $\mathrm{S}$ for Entropy and W for internal work.

The criticism is constructive and suggestive. The question arises: Is it not desirable to follow the lead of navigator and magnetician and use degrees instead of letters to indicate direction of air flow? There are some distinct gains from such a usage for the aerographer or chart maker of the winds. Official weather bureaus record direction on a 45-degree basis; that is, eight directions are given. It has long been felt that such records were not sufficiently detailed. Precision, detail and convenience are gained by the use of the degree.

There is no mechanical difficulty in getting continuous records of wind direction for the entire circle. Many forms of anemoscope give such records. Figure 6 gives such a record sheet based on one used at Blue Hill for 35 years. The eight cardinal directions are noted; but instead of 32 points of the compass, as heretofore, the intervals are at 10 degrees, and thus 36 divisional lines appear instead of the old compass point 11.25. For convenience in computation there is also introduced Greenwich Mean Civil Time, beginning at an hour appropriate for changing records on this coast, noon 75 th meridian time being 17 hours Greenwich time. The sheet, however, is adaptable to any station meridian time, by inserting the proper hour in the S.M.T. column. If, however, the centesimal system is to be used, the number of divisional lines is increased to 40 , and since there are 400 grads in the circle, each division represents 10 grads or 9 degrees.

${ }^{2}$ H. A., 83-4, pp. 169-180.

${ }^{2}$ Nature, Nov. 4, 1919. 